\title{
AC loss measurements in a hybrid REBCO/BSCCO coil assembly
}

\author{
Z. Jiang, M. Staines, N. J. Long, R. A. Badcock, C. W. Bumby, R. G. Buckley, W. Song, and N. Amemiya
}

\begin{abstract}
Wire cost and AC loss are paramount issues for the future uptake of HTS AC machines. In particular, new approaches which reduce the total manufacturing cost of HTS coils are critical to the future commercial uptake of HTS technology. Here, we present the results of AC loss measurements s of a hybrid HTS coil assembly comprising end windings (EWs) wound with BSCCO wire and a central winding (CW) wound with REBCO wire. As a cost mitigation measure, we have chosen to use REBCO wire which possesses a relatively low self-field $I_{\mathrm{c}}$ at $77 \mathrm{~K}$, equating to approximately half that of the BSCCO wire.

Transport AC loss measurements were made on the total coil assembly at both $77 \mathrm{~K}$ and $65 \mathrm{~K}$, using a recently developed lockin amplifier approach. We show the AC losses in the assembly at these temperatures scale with the overall transport critical current threshold of the hybrid coil assembly. The results are then compared with a reference coil assembly having similar geometrical dimensions, and in which both the $\mathrm{EWs}$ and $\mathrm{CW}$ were wound with identical BSCCO wire. Surprisingly we observe that the AC loss of the hybrid coil is lower than that of the BSCCO coil, despite the $\mathrm{CW}$ of the hybrid coil employing wire a lower overall average Ic. We attribute this effect to the lower AC loss of coated conductor REBCO wire under parallel field, which is the dominant field orientation in the $\mathrm{CW}$ region.
\end{abstract}

Based on this observation we conclude that hybrid assembly design is a good design strategy for HTS coil assemblies, enabling both wire cost and AC loss to be balanced.

Index Terms - AC loss, HTS, Coil assembly.

\section{INTRODUCTION}

$\mathrm{R}$ educing the $\mathrm{AC}$ loss of coil windings is a prime consideration in many AC applications of high temperature superconductor (HTS) wire, for example power transformers or fast-ramping $\mathrm{DC}$ magnets [1-5]. For a given $\mathrm{AC}$ transport current, the loss can be reduced by using wire with higher critical current, or by using a larger quantity of wire operated at a lower fraction of its critical current (to achieve the same ampturns with fewer amps and more turns). However, both of these approaches incur substantially higher manufacturing costs, as HTS wire is typically marketed on a \$ per kAm basis, and the cost of HTS wire increases rapidly with self-field $I_{\mathrm{c}}$. This is a major obstacle to technology uptake in cost-sensitive commercial applications.

Manuscript submitted November 25, 2016.

Z. Jiang, M. Staines, N. J. Long, C. W. Bumby, R. A. Badcock, R. G. Buckley are with the Robinson Research Institute, Victoria University of Wellington, PO Box 33436, Lower Hutt 5046, New Zealand. (e-mail: zhenan.jiang@vuw.ac.nz).
Two main types of HTS wire are commercially available for HTS coil applications: BSCCO filamentary wire and REBCO coated conductor wire. At the moment, the price of BSCCO wire remains significantly lower than the REBCO price for the same self-field $I_{\mathrm{c}}$ performance at $77 \mathrm{~K}$, even though there is future potential to attain lower manufacturing costs for the latter. Therefore HTS coils manufactured from BSCCO wire can generally be produced at lower cost than equivalent coils manufactured from REBCO wire. On the other hand, by using REBCO wire rather than BSCCO in a coil winding, there is the potential to reduce the AC loss in the coil winding. As a result, the literature is replete with reports of experimental and modelling studies on windings using either BSCCO or REBCO wire [2-10]. However, there are far fewer reports of hybrid coil assemblies employing either mixed wire types, or separate wires with different critical current, that are deliberately apportioned within the winding assembly.

Fig. 1(a) shows a schematic view of a typical HTS coil assembly. The local magnetic field experienced by the wire depends on its position within the coil. Wire near the ends of the winding is subjected to relatively high radial magnetic fields which are perpendicular to the face of the conductor, whilst the wire in the central section of the winding sees magnetic fields which are approximately parallel to the conductor face. The substantial difference in magnetic environment along the coil suggests that the optimal choice of wire for each region may not be the same. The aim of the present study is to investigate the potential for reducing both losses and manufacturing cost by judicious mixing of BSCCO and REBCO wire types.

\section{FIG. 1 HERE}

Recently we have reported measurements of the critical current and AC loss of three different HTS winding assemblies made of stacks of six double pancake coils (DPCs) [11]. Each set of double pancakes were fabricated from approximately 4 $\mathrm{mm}$ BSCCO and REBCO wires possessing distinctly different self-field $I_{\mathrm{c}}$ values at $77 \mathrm{~K}$. The assembly could be divided into three sections: two identical end windings (EWs) and a central winding $(\mathrm{CW})$ as shown in Fig. 1(b). Each end winding consisted of a single DPC. The central winding was made up of four double pancake coils. One assembly was wound solely from a single type of BSCCO wire with self-field $I_{\mathrm{c}}$ at $77 \mathrm{~K}$ of

W. Song is with School of Electrical Engineering, Beijing Jiaotong University, Beijing 100044, China, currently is visiting the Robinson Research Institute, Victoria University of Wellington.

N. Amemiya is with Graduate School of Engineering, Kyoto University, Kyoto, 615-8510, Japan. 
156 A (All-BSCCO). A second assembly was wound with REBCO wire (All-REBCO), in which the EWs were wound with high $I_{\mathrm{c}}$ wire $\left(I_{\mathrm{c}, \mathrm{EW}}=238 \mathrm{~A}\right)$ whilst the $\mathrm{CW}$ was wound with low $I_{\mathrm{c}}$ wire $\left(I_{\mathrm{c}, \mathrm{CW}}=86 \mathrm{~A}\right)$. A third assembly $(\mathrm{BSCCO} / \mathrm{REBCO})$ was wound with $\mathrm{BSCCO}$ for its $\mathrm{CW}$ and with high- $I_{\mathrm{c}} \mathrm{REBCO}$ for its EWs. The results from this work showed that the AC loss can be reduced by using REBCO wires for $\mathrm{CW}$ region. This is because the magnetic field in the $\mathrm{CW}$ is mostly parallel and the $\mathrm{AC}$ loss in REBCO wires due to the parallel magnetic field is small [11]. However, the lowest losses reported in that work were obtained from coil assemblies employing end windings made from expensive high $I_{\mathrm{c}}$ REBCO wire.

In this work, we have studied a new alternative hybrid coil design, which has the potential to decrease the AC losses below that of a BSCCO coil, without incurring the additional expense of high $I_{\mathrm{c}}$ REBCO end windings. In this case the coil EWs are wound with BSCCO wire, whilst its $\mathrm{CW}$ is wound with low $I_{\mathrm{c}}$ REBCO wire. We have measured the AC loss and $I_{\mathrm{c}}$ of the coil assembly $\left(I_{c}\right.$, assembly $)$ at $65 \mathrm{~K}$ and $77 \mathrm{~K}$. We have then compared the AC losses with assemblies with the All-BSCCO and AllREBCO coil assemblies reported in the previous work [11].

\section{EXPERIMENTAL METHOD}

\section{A. HTS coil assembly}

The double pancake coils (DPCs) were manufactured by HTS-110 Ltd. The coils are dry-wound without epoxy resin encapsulation. Turn-to-turn insulation is provided by Nomex aramid paper $0.05 \mathrm{~mm}$ thick co-wound with the HTS wire [11].

The coil assembly studied here consisted of a REBCO CW and two BSCCO EWs. We will refer to this arrangement as the REBCO/BSCCO assembly. The CW is wound with SCS 4050 REBCO coated conductor wire manufactured by SuperPower. The wire width is $4.0 \mathrm{~mm}$, thickness $0.1 \mathrm{~mm}$, and the self-field $I_{\mathrm{c}}=86 \mathrm{~A}$. The CW comprised a stack of four DPCs. The DPCs were identically constructed: each had 40 turns, $9 \mathrm{~mm}$ height, coil inner diameter $60 \mathrm{~mm}$, outer diameter $73 \mathrm{~mm}$. The CW included $1.5 \mathrm{~mm}$ thick G-10 spacers at the ends to give a total height of $38 \mathrm{~mm}$. Electrical connection between the neighboring DPCs consisted of ten BSCCO strips each $10 \mathrm{~mm}$ long, which were soldered in parallel to provide a low contact resistance between coils. BSCCO wire with self-field $I_{\mathrm{c}}$ of 170 A was used for these interconnects using $\operatorname{In}_{66.7} \mathrm{Bi}_{33.3}$ solder with a melting point of $72^{\circ} \mathrm{C}$. The EWs were made with AMSC $\mathrm{BSCCO}$ wire which was $4.3 \mathrm{~mm}$ wide and $0.3 \mathrm{~mm}$ thick, with average $77 \mathrm{~K}$ self-field $I_{\mathrm{c}}$ of $156 \mathrm{~A}$. The gap between the $\mathrm{CW}$ and EW was $1.5 \mathrm{~mm}$. Fig. 2(a) shows the full coil assembly.

\section{FIG. 2 HERE}

Fig. 3 (a) shows the calculated magnetic field distribution within the REBCO/BSCCO assembly for a current of $40 \mathrm{~A}$ (COMSOL ver. 5.2). This represents the peak field experienced by the coil windings when $I_{\mathrm{t}} / I_{\mathrm{c}}$, assembly $=0.72$. The flux line distribution obtained is qualitatively similar to that shown in Fig. 1. Figs. 3(b) and 3(c) show calculated variation of the radial and axial field components of the innermost, central, and outermost layers of the assembly. In both cases, we observe small amplitude fluctuations with axial position which arise due to the air gap spacing between each DPC stack. We also see that the radial field component is broadly independent of winding layer position, reaching a maximum magnitude of $100.0 \mathrm{mT}$ at either end of the assembly (axial position $= \pm 29.5 \mathrm{~mm}$ ), and a minimum magnitude of zero at the center of the assembly (axial position $\sim 0 \mathrm{~mm}$ ). In contrast, the axial field component shows a strong dependence on winding layer position, with the inner and outer winding layers within each DPC experiencing axial fields of opposite direction. The axial field magnitude reaches a maximum for both the outer and inner layers at an axial position of $0 \mathrm{~mm}$. These calculated field profiles support our assumption that axial field performance is of primary importance for wire employed in the $\mathrm{CW}$ region of the assembly.

\section{FIG. 3 HERE}

\section{B. Measurement method}

The detailed measurement method has previously been published [11]. Here we summarize the main points. Fig. 2(b) shows the measurement set-up schematic. Voltage taps connected to the end of the coil assembly were used for measurements of both $I_{\mathrm{c} \text {, assembly }}$ and $\mathrm{AC}$ loss. The coil assembly was mounted in a foam-insulated non-conductive glass reinforced polymer (GFRP) $\mathrm{LN}_{2}$ dewar [12]. The temperature of the $\mathrm{LN}_{2}$ was controlled between $77 \mathrm{~K}$ and $65 \mathrm{~K}$ by pumping on the dewar with the pressure regulated using a manostat. Two lock-in amplifiers (Stanford 830) were used for data acquisition: one measured the current phase and amplitude using an in-house two-stage current transformer, whilst the other measured the voltage difference across the coil assembly voltage taps.

The AC loss per cycle per unit conductor length of the coil assembly is given by,

$$
Q=\frac{V_{\text {rms }} I_{\text {assembly,rms }}}{f} .
$$

where $V_{\text {rms }}$ is the component of the coil assembly voltage inphase with the coil current, $I_{\text {assembly, rms }}$ is the rms value of the coil assembly current, and $f$ is the frequency of the coil assembly current.

\section{EXPERIMENTAL RESULTS}

\section{A. $I_{\mathrm{c}}$ measurement of the coil assembly}

$E-I$ curves for the REBCO/BSCCO assembly at $77 \mathrm{~K}$ and $65 \mathrm{~K}$ are shown in Fig. 4. In addition, E-I curves for the previously measured All-REBCO and All-BSCCO assemblies are also plotted in this figure for comparison [11]. The plotted curves are obtained after subtracting resistive components due to the soldered joints between DPCs. Table 1 shows the $I_{\mathrm{c}}$, assembly values at $77 \mathrm{~K}$ and $65 \mathrm{~K}$ based on the usual $1 \mu \mathrm{V} / \mathrm{cm}$ electric field criterion, together with the values for the AllBSCCO and All-REBCO assemblies. The $I_{c \text {, assembly values at } 77}$ 
K obey the relationships $I_{\mathrm{c}}(\mathrm{REBCO} / \mathrm{BSCCO}) \approx I_{\mathrm{c}}(\mathrm{All}-\mathrm{REBCO})$ $<I_{\mathrm{c}}($ All-BSCCO $)$ while at $65 \mathrm{~K} I_{\mathrm{c}}(\mathrm{REBCO} / \mathrm{BSCCO}) \approx I_{\mathrm{c}}($ All$\mathrm{BSCCO})<I_{\mathrm{c}}($ All-REBCO) . The change in relative magnitude with differing temperature is probably due to the higher $I_{\mathrm{c}}$ 'lift factor' of REBCO wires than that of BSCCO wires. The lift

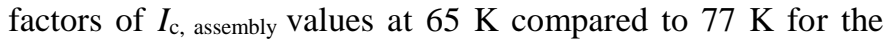
assemblies are listed in Table 1. The lift factor for the REBCO/BSCCO assembly is between that for the All-REBCO and All-BSCCO assemblies.

\section{FIG. 4 HERE TABLE I HERE}

\section{B. Coil assembly AC loss measurement}

Resistive dissipation in the contact resistances, $R_{\mathrm{c}}$, between the DPCs was confirmed to be much less than the AC loss in the HTS coil assemblies [11]. The $R_{\mathrm{c}}$ values at $77 \mathrm{~K}$ and $65 \mathrm{~K}$ are $2.29 \mu \Omega$ and $2.10 \mu \Omega$, respectively. The AC loss values for the coil assembly presented in the figures that follow are net AC loss values, with the ohmic loss component due to $R_{\mathrm{c}}$ subtracted.

Fig. 5 shows the measured AC loss in the assembly at 43.96 $\mathrm{Hz}$ and $26.62 \mathrm{~Hz}$, and at $77 \mathrm{~K}$ and $65 \mathrm{~K}$, plotted as a function of current amplitude. The AC loss results per cycle at each frequency agree very well in the high current region although there is some disagreement between the results in the low assembly-current region. This minor difference might be due to the frequency dependence of AC loss in some HTS wires [13, 14], however the frequency independence of the results at higher currents confirms that the loss is hysteretic.

Previous studies have shown that AC loss in HTS windings with AC transport current of amplitude $I_{\mathrm{t}}$ and coil critical current $I_{\mathrm{c}}$ follows a power law $\propto\left(I_{t} / I_{c}\right)^{n}$ where the exponent $n$ is between 2 and 4 [2-10]. By fitting our experimental data, we find that the loss varies with current according to a power law with exponent approximately 2.3 to 2.6 which is in accordance with previously reported values [2-11].

In the figure, the AC losses (at $26.62 \mathrm{~Hz}$ ) for the previously measured All-BSCCO assemblies also plotted for comparison. Interestingly, we observe that the $\mathrm{AC}$ loss of the hybrid coil REBCO/BSCCO is lower than that of the BSCCO coil across the full range of current amplitudes studied. This occurs despite the fact that the $\mathrm{CW}$ region of the hybrid coil employs wire with an average self-field $I_{\mathrm{c}}$ that is only approximately half of that used for the same region in the All-BSCCO assembly. The reasons behind this initially counter-intuitive observation are discussed further below.

\section{FIG. 5 HERE}

Fig. 6 shows the variation in the AC loss of the coil assembly with temperature, comparing measurements at $77 \mathrm{~K}$ and $65 \mathrm{~K}$. The measured AC loss values at $77 \mathrm{~K}$ are greater than those at $65 \mathrm{~K}$. This is due to the increase in $I_{\mathrm{c} \text {, assembly with decreasing }}$ temperature.

By analogy with the standard expressions for transport loss [15] and magnetic loss [16] in an isolated wire we expect the
AC loss will decrease with reducing $I_{t} / I_{\mathrm{c}}$, assembly , because the AC loss in the coil assembly is proportional to $I_{\mathrm{c}}$, assembly ${ }^{2}\left(I_{\mathrm{t}} / I_{\mathrm{c}}\right.$, assembly $)^{n}$. If $n=2.3-2.6$ then the loss at a constant current amplitude will decrease with increasing $I_{\mathrm{c} \text {, assembly (as loss is }}$ proportional to $I_{\mathrm{c} \text {, assembly }}{ }^{2-n}$, where $2-n<0$ ). This is consistent with our previous work [11].

\section{FIG. 6 HERE}

In Fig. 7, we compare the AC loss values in the coil assembly, at $77 \mathrm{~K}$ and $65 \mathrm{~K}$, normalized by $I_{c}$, assembly squared, $\left(I_{c} \text {, assembly }\right)^{2}$ as a function of assembly-current amplitude

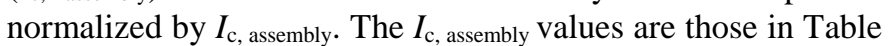
1. The scaled AC loss results at $77 \mathrm{~K}$ and $65 \mathrm{~K}$ are in good agreement. This indicates that $\mathrm{AC}$ loss can be scaled by the overall threshold transport $I_{\mathrm{c}}$ measured at the $1 \mu \mathrm{V}$ criterion across the entire series connected coil assembly. This is again consistent with previous work [11], whilst similar scaling of AC loss by the overall cable $I_{\mathrm{c}}$ have also been observed in HTS Roebel cables [12,17]. Theoretical justification of this scaling is provided by Wolfbrandt and Magnuson [18], who derived from Brandt and Indenbom [16] an expression for total AC loss in a superconductor per cycle per length, which is valid in the case of field-independent $J_{\mathrm{c}}$, with $Q=k I_{\mathrm{c}}{ }^{2} \Gamma(i, \beta)$ where $i=I_{\mathrm{t}} / I_{\mathrm{c}}$, $\beta=H / H_{\mathrm{c}}, H_{\mathrm{c}}=J_{\mathrm{c}} t / \pi$, and $t$ is thickness of superconductor. In reality, local conductor $I_{\mathrm{c}}$ in different part of the coil assembly is different. The AC loss in the coil assembly per cycle, by integrating whole length, can then be given as

$$
\begin{aligned}
& Q_{1} l_{1}+Q_{2} l_{2}+\ldots+Q_{n} l_{n}=k I_{\mathrm{cc}}^{2} \Gamma\left(i_{1}, \beta_{1}\right) l_{1} \\
& +k I_{\mathrm{c} 2}^{2} \Gamma\left(i_{2}, \beta_{2}\right) l_{2}+\ldots+k I_{\mathrm{cn}}^{2} \Gamma\left(i_{\mathrm{n}}, \beta_{\mathrm{n}}\right) l_{n} \\
& =k I_{\mathrm{c}, \text { assembly }}^{2}\left(c_{1} \Gamma\left(i_{1}, \beta_{1}\right) l_{1}+\right. \\
& \left.c_{2} \Gamma\left(i_{2}, \beta_{2}\right) l_{2}+\ldots+c_{n} \Gamma\left(i_{\mathrm{n}}, \beta_{\mathrm{n}}\right) l_{n}\right)
\end{aligned}
$$

where $I_{\mathrm{c} 1}, I_{\mathrm{c} 2}, \ldots, I_{\mathrm{cn}}$ are local conductor $I_{\mathrm{c}}$ values, $i_{1}, i_{2}, \ldots, i_{\mathrm{n}}$ are $I_{\mathrm{t}} / I_{\mathrm{c} 1}, I_{\mathrm{t}} / I_{\mathrm{c} 2}, \ldots, I_{\mathrm{t}} / I_{\mathrm{cn}}, \beta_{1}, \beta_{2}, \ldots, \beta_{\mathrm{n}}$ are $H / H_{\mathrm{c} 1}, H / H_{\mathrm{c} 2}, \ldots$, $H / H_{\mathrm{cn}}$, and $l_{1}, l_{2}, \ldots, l_{\mathrm{n}}$ are individual conductor lengths which have conductor critical currents of $I_{\mathrm{c} 1}, I_{\mathrm{c} 2}, \ldots, I_{\mathrm{cn}}$, respectively. The total conductor length of the coil assembly is given by $l=$ $l_{1}+l_{2}+\ldots+l_{\mathrm{n}}$ and $c_{1}, c_{2} \ldots c_{\mathrm{n}}$ are constant expansion coefficients defined by $\left(I_{\mathrm{c} 1} / I_{\mathrm{c}} \text {, assembly }\right)^{2},\left(I_{\mathrm{c} 2} / I_{\mathrm{c}} \text {, assembly }\right)^{2}, \ldots\left(I_{\mathrm{cn}} / I_{\mathrm{c}}\right.$, assembly $)^{2}$.

The loss in the coil will be dominated by regions where the field dependence has reduced $I_{\mathrm{c}, \mathrm{i}}$, to the point that the local $I_{\mathrm{c}, \mathrm{i}}$ $\approx I_{\mathrm{c}}$, assembly. In these regions the $c_{\mathrm{i}} \approx 1$. In higher $I_{\mathrm{c}}$ regions the $c_{\mathrm{i}}>1$, but the associated $\Gamma_{\mathrm{i}}$ values will be much lower due to the higher $I_{\mathrm{c}}$ and these terms will contribute much less to the sum. Hence Eq. (2) explains why the overall coil assembly AC loss can be scaled by the overall coil assembly $I_{\mathrm{c}}, I_{\mathrm{c}}$ assembly even considering variations in local conductor $I_{\mathrm{c}}$.

\section{FIG. 7 HERE}

In Fig. 8, we compare the AC loss at $77 \mathrm{~K}$ in the three coil assemblies normalized by the $I_{\mathrm{c}}$, assembly squared, $\left(I_{\mathrm{c}} \text {, assembly }\right)^{2}$ as a 
function of normalized coil current. The AC losses follow the order $Q(\mathrm{All}-\mathrm{BSCCO})>Q(\mathrm{REBCO} / \mathrm{BSCCO})>Q(\mathrm{All}-$ REBCO). The AC loss in the All-BSCCO assembly is greater than that in the REBCO/BSCCO assembly, due to the larger AC loss in the BSCCO $\mathrm{CW}$ than in the REBCO $\mathrm{CW}$. This arises due to the high near parallel (axial) field in the central section as can be seen in Fig. 3(b) [19]. The superconducting filamentary region of the BSCCO wire is two orders of magnitude thicker than the superconducting film thickness of the REBCO tape, around $150 \mu \mathrm{m}$ for the BSCCO wire versus 1 $\mu \mathrm{m}$ for the coated conductor. The larger dimensions in the direction of flux motion mean that the parallel field magnetic losses will be larger for BSCCO than for REBCO. Using a slab model at $100 \mathrm{mT}$ field amplitude, we estimate the loss to be reduced to $7.9 \mu \mathrm{J} \mathrm{m}^{-1}$ per cycle for the REBCO wire compared to $2.0 \mathrm{~mJ} \mathrm{~m}^{-1}$ per cycle for the BSCCO tape - a factor of around 250 less. The comparison between the REBCO/BSCCO and All-REBCO assemblies is also interesting, as they both share the same REBCO $\mathrm{CW}$. The difference between these two assemblies lies solely in the wire used to form the EWs. The YBCO EW has dimensions almost identical to the BSCCO EW, so the difference is simply due to the disparity between the two wires. The self-field $I_{\mathrm{c}}$ for the YBCO EWs is $238 \mathrm{~A}$, whilst for the BSCCO EWs $I_{\mathrm{c}}=156 \mathrm{~A}$. The $I_{\mathrm{c}}$, assembly for the All-REBCO assembly at $77 \mathrm{~K}$ is almost the same as the REBCO/BSCCO assembly as listed in Table 1 [11]. However local $I_{t} / I_{\mathrm{c}, \mathrm{EW}}$ values in the EWs of the All-REBCO assembly are smaller than the local $I_{\mathrm{t}} / I_{\mathrm{c}}$ values in the EWs of the REBCO/BSCCO assembly because of higher wire $I_{\mathrm{c}}$ values of the REBCO. Hence according to Eq. (2), AC loss in the EWs of the All-REBCO assembly should be smaller than that of the REBCO/BSCCO assembly, and this effect more than compensates for any relative reduction in REBCO wire performance in perpendicular field.

The manufacturing costs of the coil assemblies are in reverse order to the AC losses incurred, i.e. the cost of (All-BSCCO) < $(\mathrm{REBCO} / \mathrm{BSCCO})<(\mathrm{All}-\mathrm{REBCO})$ and hence provide a reverse incentive to minimizing $\mathrm{AC}$ loss.

The results above indicate that the hybrid REBCO/BSCCO assembly structure enables AC losses to be reduced below that of an All-BSSCO coil. This reduction occurs despite employing low- $I_{\mathrm{c}}$ REBCO wire for the $\mathrm{CW}$ windings - for the case studied here the self-field $I_{\mathrm{c}}$ of the REBCO wire used in the $\mathrm{CW}$ region is only half that of BSCCO wire to which it is compared [11].

\section{FIG. 8 HERE}

\section{CONCLUSION}

We have measured AC loss and coil assembly $I_{\mathrm{c}}$ at $77 \mathrm{~K}$ and $65 \mathrm{~K}$ in a HTS coil assembly which has a hybrid winding made up of a central winding wound with low self-field $I_{\mathrm{c}}$ REBCO wires, and end windings wound with BSCCO wires possessing a substantially higher self-field $I_{\mathrm{c}}$ value.

The AC losses in the coil assembly at $77 \mathrm{~K}$ and $65 \mathrm{~K}$ can be normalized by $\left(I_{\mathrm{c}} \text {, assembly }\right)^{2}$, and plotted versus the coil current normalized by the $I_{\mathrm{c}}$, assembly. This shows that the losses follow a simple frequency-independent power-law dependence on the

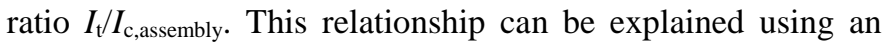
equation by Wolfbrandt and Magnuson which takes into consideration variable local conductor $I_{\mathrm{c}}$.

The AC loss in the hybrid coil assembly studied here were found to be smaller than losses incurred in a similar AllBSCCO assembly measured in previous work. However it is larger than the losses previously measured in an All-REBCO assembly which employed EWs made from very high $I_{\mathrm{c}}$ wire.

Our results imply that the design strategy of employing low $I_{\mathrm{c}}$ REBCO wire in regions of parallel field within a coil, is a valid approach when seeking to minimize both $\mathrm{AC}$ losses and manufacturing input costs. It can deliver magnet designs which exhibit lower AC loss than an All-BSCCO assembly, yet at substantially lower cost than an All-REBCO assembly employing high- $I_{\mathrm{c}}$ wire.

\section{ACKNOWLEDGMENT}

Z.J. thanks S. Spencer for SEM analysis and G. Sidorov for development of cryogenic systems.

\section{REFERENCES}

[1] S. Kalsi Application of high temperature superconductors to electric power equipment IEEE Press, New Jersey, pp. 102-106, 2011.

[2] M. P. Oomen, R. Nanke and M. Leghissa, "Modelling and measurement of ac loss in BSCCO/Ag-tape windings," Supercond. Sci. Technol., vol. 16, pp. 339-54, 2003.

[3] E. Pardo, M. Staines, Z. Jiang and N. Glasson, "AC loss modelling and measurement of superconducting transformers with coated-conductor Roebel-cable in low-voltage winding," Supercond. Sci. Technol., vol. 28, 2015, Art ID 114008.

[4] M. D. Ainslie, V. M. Rodriguez-Zermeno, Z. Hong, W. Yuan, T. J. Flack and T. Coombs, "An improved FEM model for computing transport AC loss in coils made of RABiTS YBCO coated conductors for electric machines," Supercond. Sci. Technol., vol. 24, 2011, Art ID 045005.

[5] M. Zhang, W. Yuan, J. Kvitkovic and S. Pamidi, "Total AC loss study of 2G HTS coils for fully HTS machine applications," Supercond. Sci. Technol., vol. 28, 2015, Art ID 115011.

[6] E. Pardo, J. Šouc and J. Kováč, "AC loss in ReBCO pancake coils and stacks of them: modelling and measurement," Supercond. Sci. Technol., vol. 25, 2012, Art ID 035003.

[7] L. Queval, V. M. R. Zermeno and F. Grilli, "Numerical models for ac loss calculation in large-scale applications of HTS coated conductors," Supercond. Sci. Technol., vol. 29, 2016, Art ID 02407.

[8] F. Gömöry, J. Šouc, E. Pardo, E. Seiler, M. Soloviov, L. Frolec, M. Skarba, P. Konopka, M. Pekarčíková and J. Janovec J, "AC loss in pancake coil made from $12 \mathrm{~mm}$ wide REBCO tape," IEEE Trans. Appl. Supercond., vol. 22, 2013, Art ID 5900406.

[9] Z. Jiang, N. J. Long, R. A. Badcock, M. Staines, R. A. Slade, A. D. Caplin and N. Amemiya, "AC loss measurements in pancake coils wound with $2 \mathrm{G}$ tapes and Roebel cable: dependence on spacing between turns/strands," Supercond. Sci. Technol., vol. 25, 2012, Art ID 035002.

[10] D. N. Nyuyen, C. H. Kim, J. H. Kim, S. Pamidi and S. P. Ashworth, "Electrical measurements of AC losses in high temperature superconducting coils at variable temperatures," Supercond. Sci. Technol., vol. 26, 2013, Art ID 095001.

[11] Z. Jiang, N. J. Long, M. Staines, R. A. Badcock, C. W. Bumby, R. G. Buckley, and N. Amemiya, "AC loss measurements in HTS coil assemblies with hybrid coil structures," Supercond. Sci. Technol., vol. 29, 2016, Art ID 095011.

[12] Z. Jiang, N. J. Long, M. Staines, R. Badcock, R. G. Buckley, E. Talantsev and N. Amemiya, "The dependence of transport AC loss on temperature and DC parallel magnetic field in an eight-strand YBCO Roebel cable," IEEE Trans. Appl. Supercond., vol. 23, 2013, Art ID 5402604.

[13] N. Banno and N. Amemiya, "Analytical formula of coupling loss and hysteresis loss in HTS tape,” Cryoginics, vol. 39, pp. 99-106, 1999. 
[14] L. S. Lakshmi, N. J. Long, R. A. Rodback, M. P. Staines, Z. Jiang, K. P. Thakur and J. Emhofer, "Magnetic and transport AC losses in HTS Roebel cable," IEEE Trans. Appl. Supercond., vol. 21, pp. 3311-3315, 2011.

[15] W. T. Norris, "Calculation of hysterisis losses in hard superconductor carrying AC: Isolated conductors and edges of thin sheets," J. Phys. D: Appl. Phys. vol. 3, pp.489-507, 1970.

[16] E. H. Brandt and M. Indenbom, "Type-II-superconductor strip with current in a perpendicular magnetic field," Phys. Rev. B, vol. 43 pp. 12893-12906, 1993.

[17] Z. Jiang, M. Staines, N. Long, R. Badcock, C. Bumby, E. Talantsev, K Hamilton, R. Buckley and N. Amemiya, "The scaling of transport AC losses in Roebel cables with varying strand parameters," Supercond. Sci. Technol., vol. 27, 2014, Art ID 075007.

[18] A. Wolfbrandt and N. Magnusson, "AC losses in high-temperature superconducting tapes exposed to perpendicular magnetic fields combined with transport currents," Supercond. Sci. Technol., vol. 15, pp. $572-576,2002$.

[19] Z. Jiang and N. Amemiya, "Comparison of the total AC loss characteristics in YBCO conductors and BSCCO multifilamentary tapes with identical engineering critical current densities" Supercond. Sci. Technol., vol. 19, pp. 742-747, 2006.

Table $1 . I_{\mathrm{c} \text {, assembly }}$ values at $77 \mathrm{~K}$ and $65 \mathrm{~K}$

\begin{tabular}{lccc}
\hline $\begin{array}{l}\text { Name of coil } \\
\text { assembly }\end{array}$ & $\begin{array}{c}I_{\mathrm{c}, \text { assembly }} \text { at } \\
77 \mathrm{~K}(\mathrm{~A})\end{array}$ & $\begin{array}{c}I_{\mathrm{c} \text {, assembly }} \text { at } \\
65 \mathrm{~K}(\mathrm{~A})\end{array}$ & $\begin{array}{c}I_{\mathrm{c} \text {, assembly at } 65 \mathrm{~K}} / \\
I_{\mathrm{c}, \text { assembly at } 77 \mathrm{~K}}\end{array}$ \\
\hline REBCO/BSCCO & 55.0 & 110.4 & 2.0 \\
All-REBCO [11] & 55.5 & 117.2 & 2.11 \\
All-BSCCO [11] & 63.6 & 110.1 & 1.73 \\
\hline
\end{tabular}

(a)

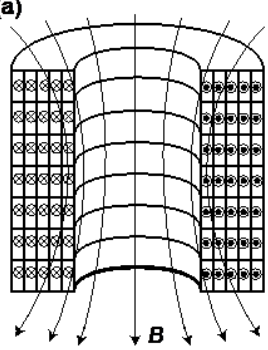

(b)

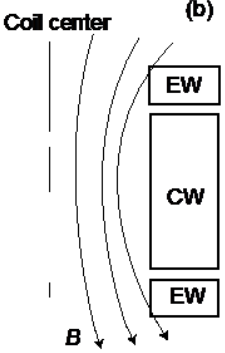

Fig. 1. (a) Schematics of magnetic field distribution in an HTS magnet and (b) the schematic of HTS assemblies [11]
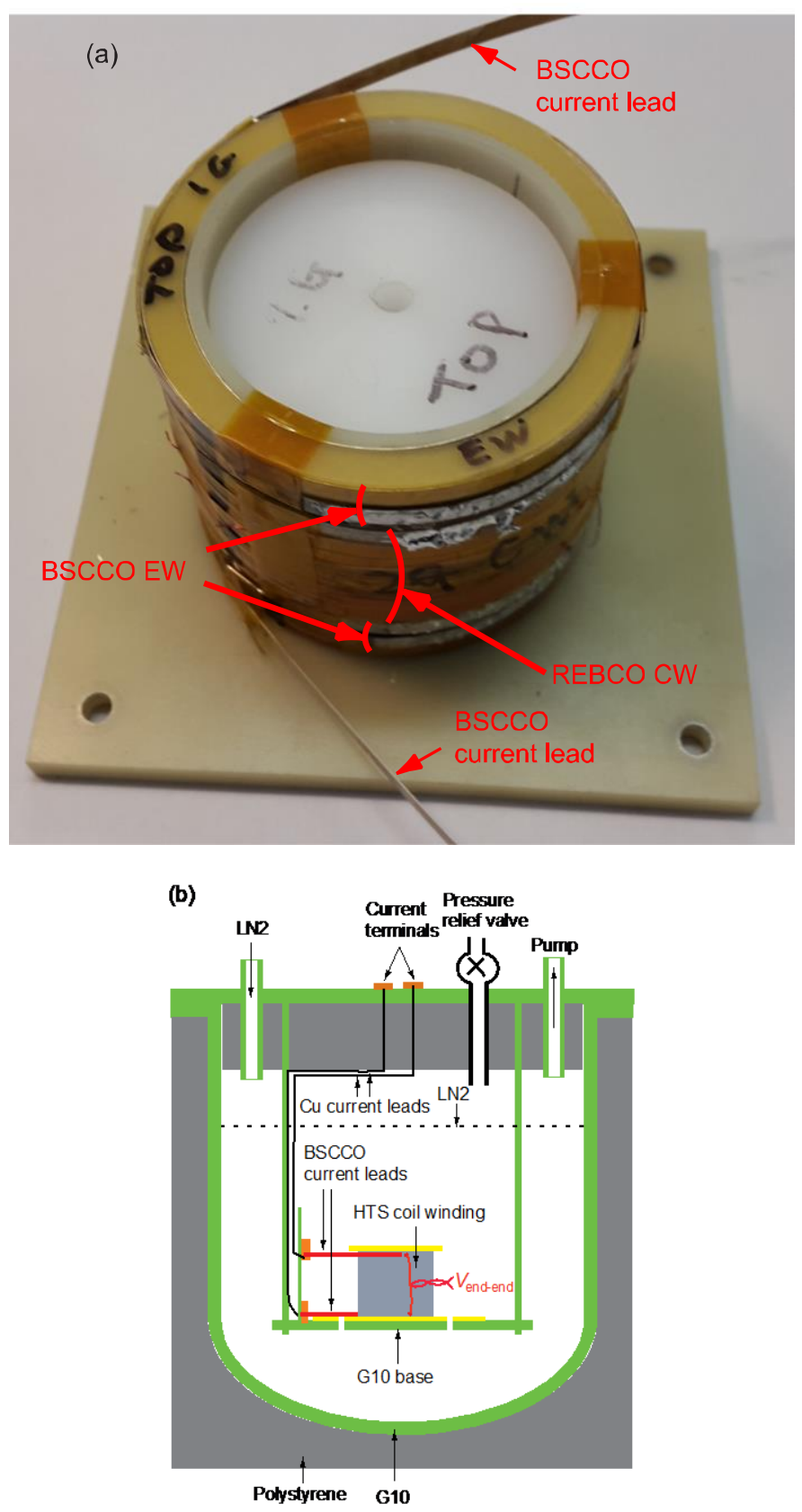

Fig. 2. (a) Assembled HTS coil assembly with REBCO CW and BSCCO EWs, (b) the schematic of measurement set-up. 
(a)
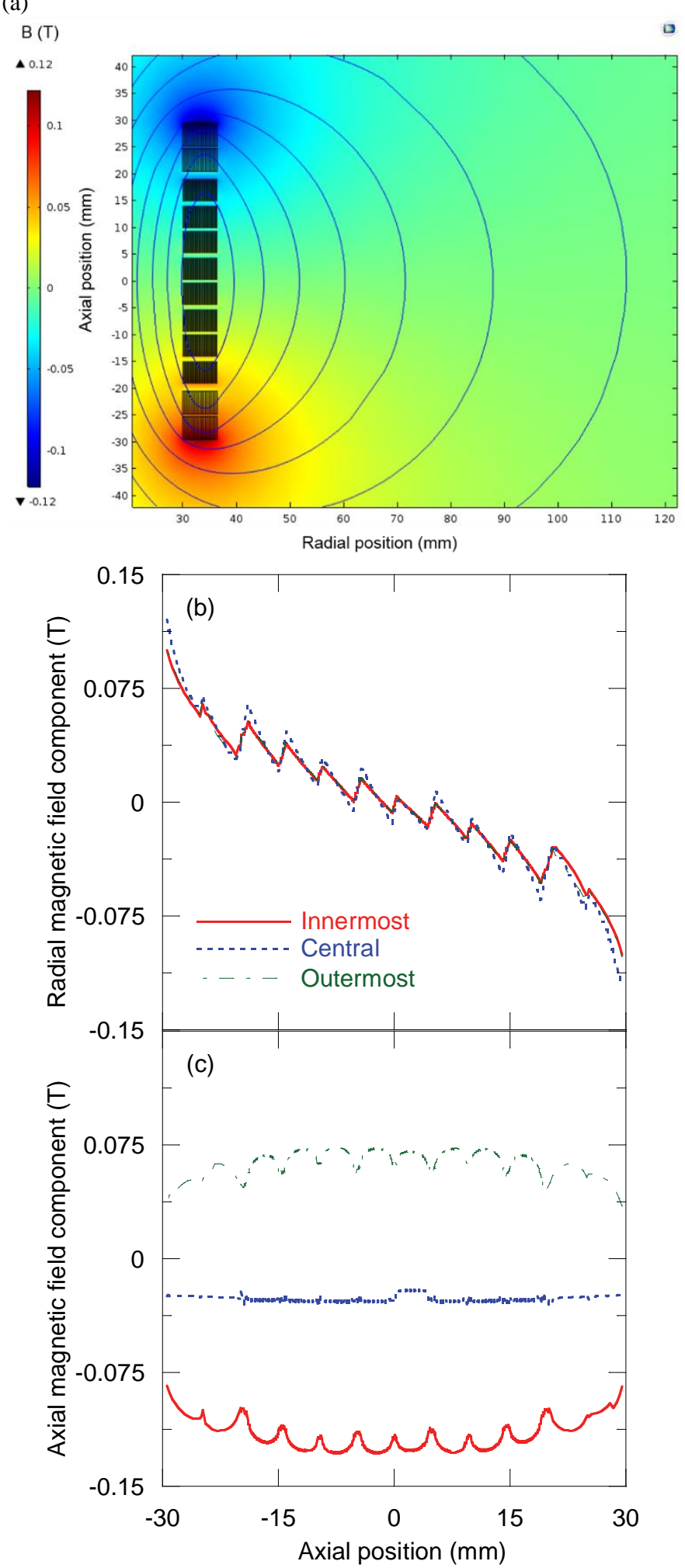

Fig. 3. (a) Calculated magnetic field distribution around REBCO/BSCCO assembly using COMSOL Multiphysics for a current of $40 \mathrm{~A}\left(I_{I} / I_{\mathrm{c}}\right.$, assembly $=$ 0.72), (b) calculated variation of the radial field components of the innermost, central, and outermost layers of the assembly, and (c) calculated variation of the axial field components of the innermost, central, and outermost layers of the assembly.

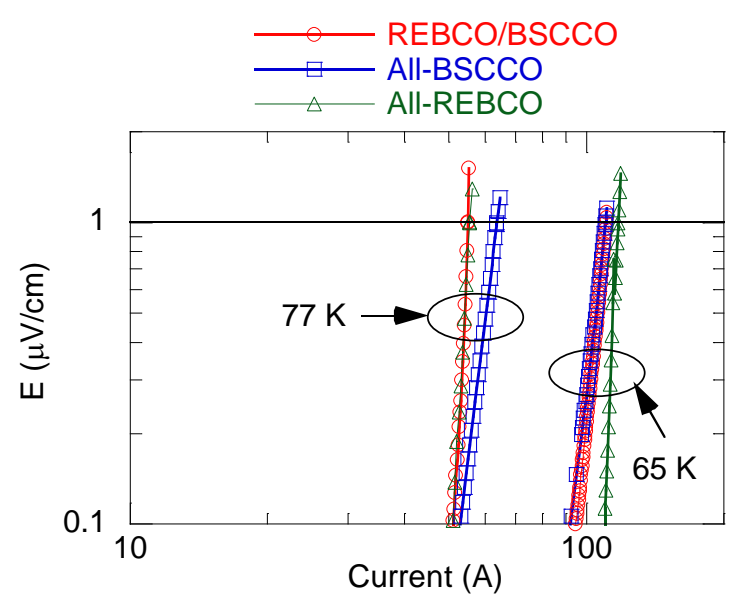

Fig. 4. Measured $I_{\text {c, assembly }}$ values in the REBCO/BSCCO assembly at $77 \mathrm{~K}$ and $65 \mathrm{~K}$. The curves for All-REBCO and All-BSCCO assemblies are for references [11].

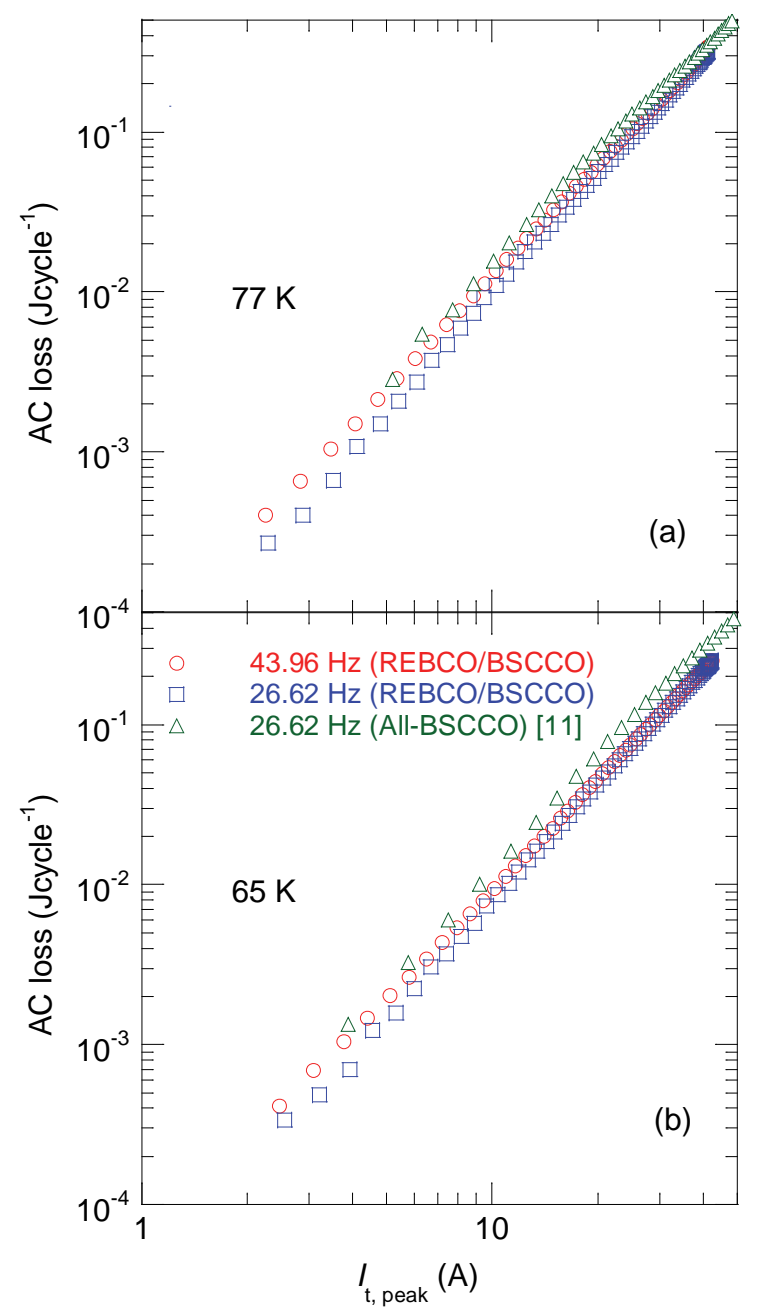

Fig. 5. Measured coil AC loss results in the REBCO/BSCCO assembly (a) 77 K, (b) $65 \mathrm{~K}$. 


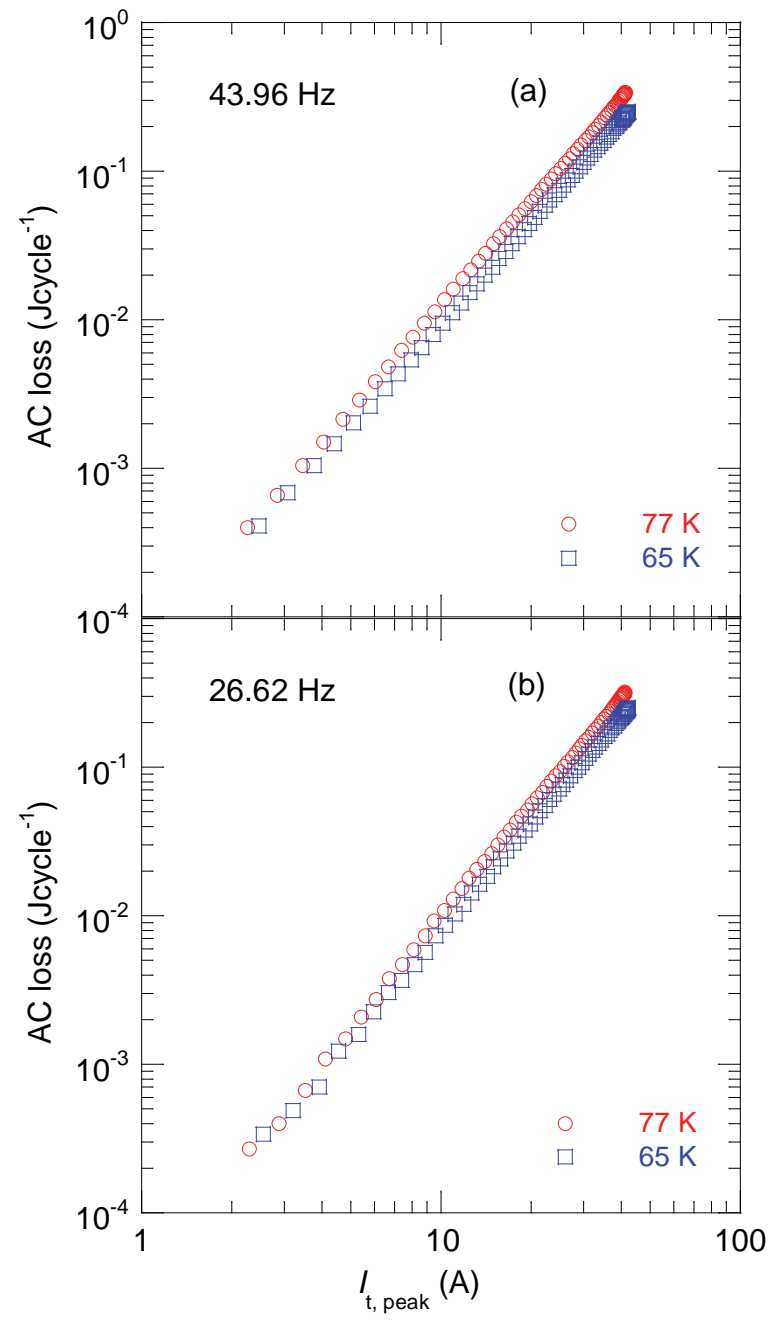

Fig. 6. Comparison of AC losses in the REBCO/BSCCO at $77 \mathrm{~K}$ and $65 \mathrm{~K}$ (a) $43.96 \mathrm{~Hz}$, (b) $26.62 \mathrm{~Hz}$.

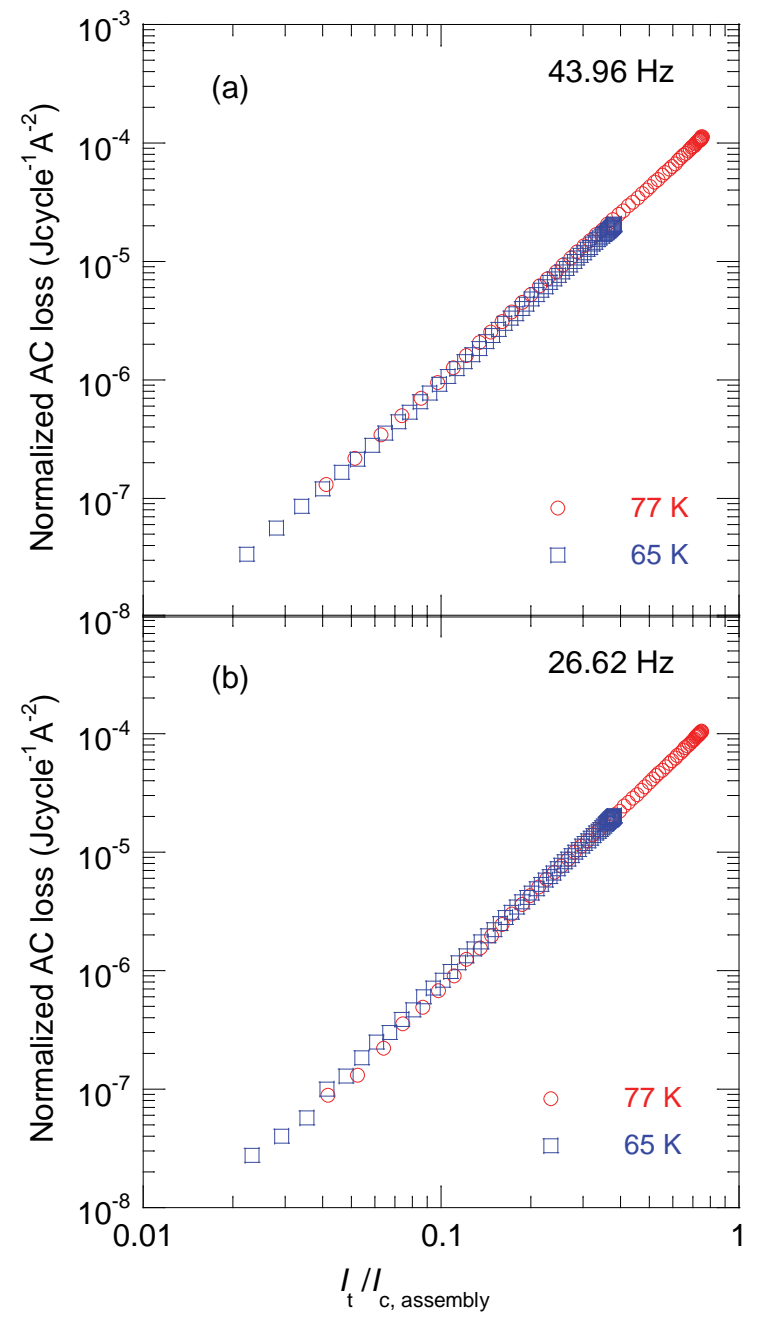

Fig. 7. Comparison of normalized AC losses in the REBCO/BSCCO at $77 \mathrm{~K}$ and $65 \mathrm{~K}$ (a) $43.96 \mathrm{~Hz}$, (b) $26.62 \mathrm{~Hz}$.

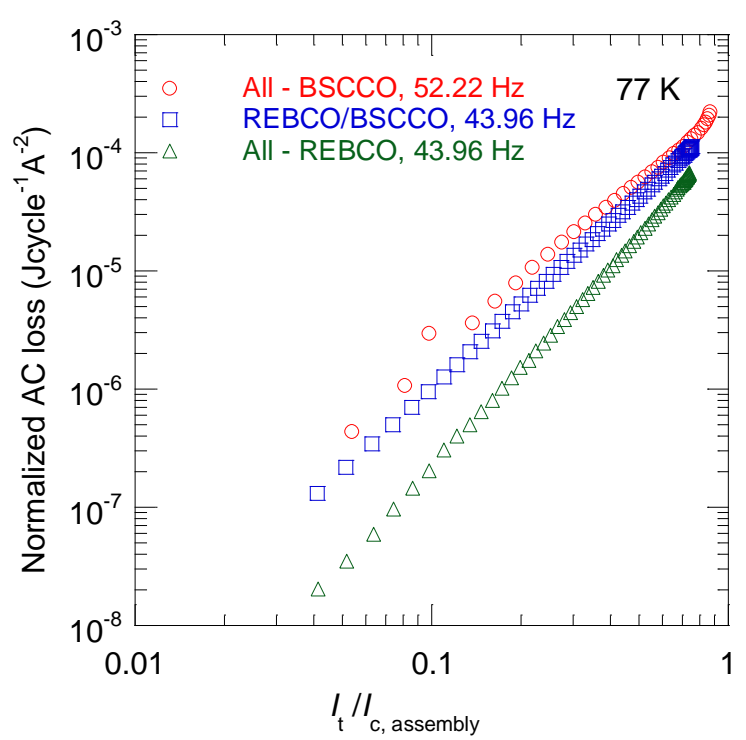

Fig. 8. Comparison of normalized AC losses in REBCO/BSCCO, All-REBCO, and All-BSCCO assemblies at $77 \mathrm{~K}$. 